\title{
Fatores de ajustamento da produção de leite, de gordura e de proteína para idade em bovinos mestiços europeu-zebu
}

\author{
[Age adjustment factors for milk, fat and protein yield of crossbred European-Zebu cattle] \\ G. Carvalho ${ }^{1}$, A.F. Freitas ${ }^{2}$, J. Valente $^{2}$, P.C.N. Azevedo ${ }^{3}$ \\ ${ }^{1}$ Manufaturação de Produtos para Alimentação Animal Premix Ltda. \\ Rodovia Engenheiro Ronan Rocha, Km 21,4 \\ 14415-000 - Patrocínio Paulista, SP \\ ${ }^{2}$ Embrapa Gado de Leite - Juiz de Fora, MG. \\ ${ }^{3}$ Universidade Federal Rural do Rio de Janeiro - Depto. de Genética - Seropédica, RJ
}

Recebido para publicação em 28 de agosto de 2000

Recebido para publicação, após modificações, em 5 de novembro de 2001.

E-mail: cargiane@bol.com.br

\section{RESUMO}

Estimaram-se os fatores de ajustamento das produções de leite, de gordura e de proteína para idade da vaca na época do parto e avaliaram-se geneticamente touros e vacas, em rebanhos de animais cruzados Europeu-Zebu, na Região Sudeste do Brasil. As 3.327 lactações foram analisadas por meio da metodologia de modelos mistos, em modelo animal, usando-se o aplicativo MTDFREML, com efeitos fixos de rebanho-ano, estação do parto, composição genética e classes de idade e efeitos aleatórios de animal e de meio permanente. Os fatores de ajustamento obtidos para produção de leite foram ligeiramente menores do que os de gordura, porém em idades mais avançadas os fatores foram semelhantes. Os fatores de ajustamento da produção de proteína tenderam a ser maiores do que os correspondentes para produção de leite e gordura. Vacas jovens tiveram fatores ligeiramente maiores do que vacas de idades mais avançadas, em todas as características estudadas. Os baixos valores das correlações estimadas entre os dados ajustados e não ajustados para idade ao parto indicaram que os fatores foram adequados.

Palavras-chave: Bovinos cruzados, fatores de ajustamento, gordura, idade, leite, proteína

\begin{abstract}
Age at calving adjustment factors for milk, fat and protein yield were obtained and the genetic values of sires and cows of crossbred European $x$ Zebu animals in the Southeastern region of Brazil were predicted. Statistical analyses of 3,327 lactations were carried out with an animal model using the MTDFREML programs, which included the fixed effects of herd-year, calving season, genetic composition, age class and the random effects of the animal, and of the permanent environment. The adjustment factors for milk yield were slightly smaller than those for fat yield but for the older animals these factors were similar. The adjustment factors for protein production tended to be higher than the correspondent ones for milk and fat production. The adjustment factors for young cows were slightly higher than that for the older ones for all the studied traits. The estimated correlation between non adjusted and adjusted data for age at calving indicated that the adjustment factors were appropriate.
\end{abstract}

Keywords: Adjustment factors, age, crossbred dairy cows, fat, milk, protein 


\section{INTRODUÇÃO}

A idade da vaca na época do parto tem sido considerada importante fator de variação no comportamento das características de produção. $\mathrm{O}$ aumento da produção de leite de acordo com a idade da vaca deve-se ao seu progressivo desenvolvimento fisiológico até a maturidade, pois é conhecido que vacas jovens têm suas necessidades nutritivas dirigidas para três funções distintas, crescimento, lactação e mantença. A capacidade orgânica, digestiva, cardiorrespiratória e o funcionamento da glândula mamária estão plenamente desenvolvidas na vaca adulta. Nessa fase da vida elas destinam os nutrientes apenas para os processos de produção, reprodução e manutenção.

Os fatores de ajustamento para o efeito de idade são necessários para avaliação genética de vacas quando animais de diferentes idades são comparados. Diversas metodologias de estimação desses fatores estão disponíveis, sendo as preferidas as que envolvem a máxima verosimilhança ou máxima verossimilhança restrita. Miller et al. (1970) estimaram fatores de ajustamento de idade e época do parto para produção de leite de vacas da raça Holandesa do Nordeste dos EUA, pelo método de máxima verossimilhança. Os autores verificaram que o não ajuste simultâneo para idade e época do parto podiam produzir vieses nas avaliações genéticas.

Gacula et al. (1968) avaliaram os efeitos de idade da vaca em cinco rebanhos leiteiros (Ayrshire, Guernsey, Holandesa, Jersey e Pardo-Suíço) nos EUA para características de produção de leite, gordura, proteína, sólidos não-gordurosos e sólidos totais. Um grupo de fatores multiplicativos foi estimado para cada característica. Os autores concluíram que existe necessidade de ajuste dos dados para cada raça e sugeriram dois grupos de fatores, um para produção de leite e outro para produção de gordura, proteína, sólidos não-gordurosos e sólidos totais.

Em gado mestiço leiteiro a tendência de aumento curvilíneo da produção de leite, de acordo com a idade da vaca, resulta em idade de produção mais elevada do que em gado leiteiro europeu (Nobre, 1983). Em vacas da raça Holandesa, Ribas et al. (1983) encontraram produções máximas à idade de 85 meses, enquanto Durães et al. (1999), no Estado de Minas Gerais, constataram que a produção máxima ocorreu entre 69 e 75 meses de idade. Na raça Gir, Martinez et al. (1992) observaram que a idade adulta ocorreu entre 93-98 meses, menor do que a encontrada por Ramos (1984), de 139 meses. De modo geral, a maturidade das vacas zebuínas ocorre mais tardiamente em relação à das vacas mestiças ou à das raças européias.

O objetivo do presente estudo foi o de estimar fatores de ajustamento das produções de leite, gordura e proteína até 305 dias de lactação, segundo a idade ao parto e avaliar geneticamente touros e vacas em rebanhos de animais cruzados Europeu-Zebu, na Região Sudeste do Brasil.

\section{MATERIAL E MÉTODOS}

Foram utilizadas lactações de vacas mestiças das seguintes composições genéticas: 1/2, 5/8, 3/4 e 7/8 Europeu (principalmente Holandês) x Zebu (Gir ou Guzerá). Os dados coletados no período de 1983 a 1997, principalmente na Região Sudeste, correspondiam a vacas filhas de 102 touros mestiços (5/8, 3/4 e 7/8 Europeu-Zebu) provenientes do Arquivo Zootécnico Nacional, gerenciado pela Embrapa Gado de Leite. As idades ao parto foram distribuídas em nove classes.

Uma vez satisfeitas todas as restrições impostas, como eliminação de dados discrepantes, lactações com duração inferior a 120 dias e ordem de lactação inferior a 10 dentro da classe rebanho-ano, restaram 3.327 registros de lactação para o estudo da produção de leite. Em relação à produção de gordura obtiveram-se 1.854 registros, e à produção de proteína somente 1.089 , em consequiência da não coleta de amostras nas propriedades e às perdas na conservação do material antes de chegar ao laboratório. 
Pela metodologia de modelos mistos adotou-se modelo animal usando máxima verossimilhança restrita (REML), por meio do programa MTDFREML (Boldman et al., 1995), com o modelo: $\mathbf{Y}=\mathbf{H h}+\mathbf{Z a}+$ $\mathbf{Z p}+\boldsymbol{\varepsilon}$, em que $\mathbf{Y}$ é o vetor das observações da produção de leite, gordura e proteína até 305 dias, $\mathbf{H}$ é a matriz de incidência dos efeitos fixos rebanho-ano, estação do parto, composição genética e classes de idade, $\mathbf{Z}$ é a matriz de incidência dos efeitos aleatórios, $\boldsymbol{\varepsilon}$ é o vetor de efeitos residuais, $\mathbf{h}$ é o vetor dos efeitos fixos, a é o vetor de efeitos aleatórios de animal e p é o vetor dos efeitos permanentes aleatórios inerentes à repetição das observações de cada vaca.

Para obtenção dos fatores, foi feita a "suavização" das constantes obtidas pelo modelo de análise, para cada classe de idade levando-se em conta o seguinte modelo: Constante $=\mathbf{a}+\mathbf{b x}+\mathbf{b x}^{2}$, em que $\mathbf{x}$ representa os efeitos linear e quadrático da idade ao parto sobre as constantes e a e b os parâmetros do polinômio. Os fatores multiplicativos de ajustamentos da produção de leite, gordura e proteína para classes de idade foram obtidos das constantes estimadas para cada classe somadas à média geral $\mu$ para se obter a média de produção para cada classe de idade. $O$ fator foi calculado pela fórmula: $\mathbf{F a t o r}=(\mu+\mathbf{y a})$ / $(\mu+\mathbf{y c})$, em que $\mu$ é a média geral, ya é a constante da idade ao parto para as vacas que pariram com idade maior do que 87 meses (idade à maturidade) e yc é a estimativa do efeito da idade ao parto para determinada classe de idade.

Para verificar os efeitos dos ajustamentos da produção para idade ao parto nas estimativas das PTAs (capacidade prevista de transmissão) dos touros foi utilizada somente a produção de leite. Três conjuntos de dados foram formados variando o número de filhas por touro da seguinte forma: $\geq 10$ filhas (conjunto 1), $\geq 20$ filhas (conjunto 2) e $\geq 30$ filhas por touro (conjunto 3), e outro conjunto com os dados completos. Os fatores são melhores testados quando se utilizam dados que não pertencem ao mesmo conjunto em que eles foram estimados, razão pela qual foram definidos esses três conjuntos. As produções em cada um desses conjuntos foram ajustadas para 305 dias de lactação e idade adulta usando-se fatores obtidos com os dados originais e os touros avaliados após o ajustamento. O modelo usado nas avaliações foi o mesmo já descrito, com exclusão da idade. Para averiguar se os ajustamentos foram eficientes, utilizaram-se a correlação entre as PTAs, pelo método de Spearman e pelo método de Pearson e a correlação de ordem dos 10 primeiros touros.

\section{RESULTADOS E DISCUSSÃO}

A produção de leite média em até 305 dias foi de $2.009 \pm 667 \mathrm{~kg}$, com coeficiente de variação de $33,2 \%$,. Uma das maiores médias de produção de leite em animais mestiços foi relatada por Camargo (1994), no Estado do Rio de Janeiro, com 4.939₫40kg, bem superior à deste estudo e com menor variação.

Para as produções de gordura e de proteína, nessa ordem, as médias e respectivos desvios-padrão e coeficientes de variação foram: $67,6 \pm 20,9 \mathrm{~kg}, 30,9 \%, 64,8 \pm 16,0 \mathrm{~kg}$ e $24,8 \%$. A produção média de gordura foi menor do que a encontrada por Ribas et al. (1983), 204kg em vacas holandesas. Em geral a produção média de gordura em áreas tropicais e subtropicais é em torno de $173 \mathrm{~kg}$ (Campos et al., 1994). A média e o coeficiente de variação para produção de proteína foram menores do que para produção de gordura, mas estão dentro dos limites de produção para animais mestiços, como relatado por Madalena et al. (1996), que encontraram valores menores do que os deste estudo, em torno de $35,9 \mathrm{~kg}$ para proteína e de $47,5 \mathrm{~kg}$ para gordura.

As análises de regressão da produção de leite, gordura e proteína em relação à idade ao parto possibilitaram identificar efeitos lineares e quadráticos. Isto implica na necessidade de se fazer o ajustamento levando-se em conta fatores específicos para cada classe de idade.

As nove classes de idade ao parto estão listadas na primeira coluna da esquerda na Tab. 1.

Os fatores de ajustamento das produções de leite, gordura e proteína variaram pouco de uma classe para outra (Tab. 1). A maior diferença, cerca de 0,08 , ocorreu na produção de gordura entre as classes 1 e 2 ; as menores, cerca de 0,01 , entre as quatro últimas classes de idade, para todas as características analisadas. 
Fatores de ajustamento da produção de leite, de gordura...

Martinez (1991) obteve fatores multiplicativos para o ajuste simultâneo dos efeitos de idade e estação do parto na raça Holandesa no Brasil. O fator de ajustamento da produção de leite na classe de 34 a 36 meses na estação da seca foi próximo de 1,20, maior do que o encontrado neste estudo para idade abaixo de 36 meses, cerca de 1,16. Os fatores de ajustamento de gordura são inferiores aos descritos por Durães \& Keown (1991), para animais da raça Holandesa com menos de 36 meses de idade, nos EUA.

Tabela 1. Fatores de ajustamento da produção de leite, de gordura e de proteína de acordo com as classes de idade

\begin{tabular}{ccccc}
\hline Classe de idade & Idade (mês) & Produção de leite & Produção de gordura & Produção deproteína \\
\hline 1 & $<36$ & 1,16 & 1,22 & 1,22 \\
2 & $36-41$ & 1,10 & 1,14 & 1,16 \\
3 & $42-50$ & 1,06 & 1,08 & 1,11 \\
4 & $51-56$ & 1,03 & 1,04 & 1,07 \\
5 & $57-62$ & 1,00 & 1,01 & 1,04 \\
6 & $63-68$ & 0,99 & 0,99 & 1,02 \\
7 & $69-74$ & 0,99 & 0,99 & 1,01 \\
8 & $75-87$ & 0,99 & 0,99 & 1,00 \\
9 & $\geq 87$ & 1,00 & 1,00 & 1,00 \\
\hline
\end{tabular}

Os fatores de ajustamento da produção de leite, gordura e proteína seguiram a mesma tendência de diminuição até a classe 6. Para idades menores, os fatores de ajustamento para gordura são maiores do que os correspondentes para produção de leite e os de proteína maiores do que os de gordura. Gacula et al. (1968) analisaram parâmetros genéticos e ambientes em rebanhos leiteiros nos EUA e encontraram fatores de ajustamento para leite e gordura maiores do que os correspondentes para proteína, ao contrário dos resultados encontrados neste estudo. Keown \& Everett (1985) encontraram fatores para produção de gordura e proteína maiores do que os correspondentes para leite e determinaram que há necessidade de separar os fatores para cada característica.

Na Tab. 2 observa-se o sumário do efeito do ajustamento da produção de leite para idade ao parto sobre as PTAs dos touros com dados completos e dados de três conjuntos de amostras, diferenciados pelo número de filhas por touro. A média das diferenças entre as PTAs estimadas com dados ajustados e nãoajustados para idade foi de $10,440 \mathrm{~kg}$, variando de $8,653 \mathrm{~kg}$ no conjunto completo a $13,404 \mathrm{~kg}$ no conjunto 3 (30 filhas por touro), indicando que os fatores foram adequados para os dados, isto é, quanto menor a diferença, melhor o ajuste dos dados. Os valores das correlações entre as PTAs pelos métodos de Spearman e de Pearson foram elevados. Neste último método os valores tenderam a ser maiores porque esse tipo de correlação leva em consideração uma classificação mais ampla entre os valores genéticos dos touros. Quando a correlação se aproxima do valor 1 significa que os fatores não estão ajustando adequadamente e não seria necessário ajustar a produção de leite para comparar as PTAs dos touros. Os valores da correlação de ordem pelo método de Spearman entre os 10 primeiros touros foram baixos, de 0,60 a 0,75 . Quando são baixos indicam que a ordem dos touros pelas suas PTAs para produção de leite depende dos ajustamentos para idade ao parto, ou seja, os valores não-ajustados são diferentes dos ajustados e ocorrem mudanças na classificação dos touros, ou até exclusão de alguns touros das primeiras classificações. Segundo Thompson et al. (1982), diferenças na relação entre as PTAs obtidas de dados de produção de leite ajustada e não ajustada determina a precisão das avaliações, demostrando correlações mais elevadas entre as PTAs pelo método de Spearman. 
Tabela 2. Efeito do ajustamento da produção de leite até 305 dias para idade ao parto sobre as PTAs dos touros com dados completos e em três conjuntos de dados, com $\geq 10, \geq 20$ e $\geq 30$ filhas por touro

\begin{tabular}{|c|c|c|c|c|}
\hline Item & Conjunto completo & Conjunto 1 & Conjunto 2 & Conjunto 3 \\
\hline Número mínimo de filhas/touro & 3 & 10 & 20 & 30 \\
\hline Número de touros & 102 & 86 & 74 & 54 \\
\hline Número de vacas & 3.327 & 3.216 & 3.063 & 2.590 \\
\hline Média das diferenças entre as PTAs $(\mathrm{kg})$ & 8,653 & 9,646 & 10,085 & 13,404 \\
\hline Desvios-padrão das diferenças (kg) & 0,695 & 0,766 & 0,808 & 1,227 \\
\hline Máxima diferença absoluta (kg) & 31,568 & 30,904 & 29,642 & 34,593 \\
\hline Correlação ${ }^{1}$ & 0,97 & 0,97 & 0,96 & 0,96 \\
\hline Correlação $^{2}$ & 0,98 & 0,97 & 0,97 & 0,97 \\
\hline Correlação $^{3}$ & 0,60 & 0,73 & 0,75 & 0,65 \\
\hline
\end{tabular}

${ }^{1}$ Correlação pelo método de Spearman entre as PTAs.

${ }^{2}$ Correlação pelo método de Pearson entre as PTAs.

${ }^{3}$ Correlação de ordem pelo método de Spearman entre os dez primeiros touros.

A exclusão de touros entre os 10 primeiros e a troca de posições entre eles refletem a necessidade dos ajustamentos para produção de leite para idade antes de se estimar as PTAs dos touros. Na Tab. 3 observa-se que somente os dois primeiros touros apresentaram a mesma classificação com dados ajustados e não-ajustados e que ocorreram algumas mudanças com inclusões e exclusões de touros entre os 10 primeiros. No conjunto 3, por exemplo, a correlação de ordem pelo método de Spearman foi baixa e os ajustamentos atuaram mais adequadamente sobre as PTAs desses animais. As diferenças entre as PTAs apresentadas na Tab. 3 indicam que a menor diferença $(0,200)$ ocorreu quando os valores das PTAs foram bem próximos e a maior $(-22,196)$ quando houve contrastes entre as PTAs, o que resultou em mudança de posições na classificação dos touros, e inclusão de animais que não estavam na classificação inicial.

Tabela 3. Classificação dos 10 primeiros touros pelas PTAs da produção de leite até 305 dias, com os conjuntos de dados não-ajustados (PTA1) e ajustados (PTA2) para idade, ordenado pelo conjunto ajustado (classificação 2) e pelo conjunto 3 ( $\geq 30$ filhas por touro)

\begin{tabular}{|c|c|c|c|c|c|c|c|}
\hline \multirow{2}{*}{ Nome do touro } & \multirow{2}{*}{ CG do touro } & \multirow{2}{*}{$\begin{array}{l}\mathrm{N}^{\mathrm{o}} \mathrm{de} \\
\text { filhas }\end{array}$} & \multicolumn{4}{|c|}{ Produção de Leite } & \multirow{2}{*}{$\begin{array}{c}\text { Diferença } \\
\text { entre as PTAs }\end{array}$} \\
\hline & & & PTA 1 & Classificação 1 & PTA 2 & Classificação 2 & \\
\hline Cacique da Prata & $7 / 8$ & 35 & 178,373 & 1 & 177,472 & 1 & 0,901 \\
\hline Oceano da São José & $3 / 4$ & 80 & 162,979 & 2 & 162,779 & 2 & 0,200 \\
\hline Zabelê da Prata & $7 / 8$ & 73 & 84,501 & 4 & 101,149 & 3 & $-16,648$ \\
\hline Uca do CNPGL & $3 / 4$ & 50 & 64,497 & 6 & 86,502 & 4 & $-22,005$ \\
\hline Nimbo da EPAMIG & $7 / 8$ & 60 & 96,994 & 3 & 86,148 & 5 & 10,846 \\
\hline Remo do CNPGL & $7 / 8$ & 76 & 54,469 & 11 & 76,665 & 6 & $-22,196$ \\
\hline Lindoio da Graminha & $5 / 8$ & 31 & 55,559 & 9 & 73,008 & 7 & $-17,449$ \\
\hline Nuvem da Graminha & $5 / 8$ & 43 & 72,515 & 5 & 62,732 & 8 & 9,783 \\
\hline Doqueiro da Prata & $7 / 8$ & 48 & 54,538 & 10 & 58,767 & 9 & $-4,229$ \\
\hline Juparanã do CNPGL & $3 / 4$ & 66 & 45,580 & 13 & 57,904 & 10 & $-12,324$ \\
\hline
\end{tabular}

PTA 1 - não-ajustado para idade ao parto; PTA 2 - ajustado para idade ao parto; CG - composição genética

\section{CONCLUSÕES}

Existem pequenas diferenças entre os fatores de ajustamento estimados para produção de leite, de gordura e proteína. Nas classes de animais mais jovens e intermediários, as diferenças entre os fatores foram maiores, indicando a necessidade de se usar fatores específicos para cada característica. As baixas correlações entre as PTAs dos touros para dados ajustados e não-ajustados da produção de leite indicam que os fatores de ajustamento foram efetivos para a correção das diferenças entre idades, quando da avaliação genética dos animais. 


\section{REFERÊNCIAS BIBLIOGRÁFICAS}

BOLDMAN, K.G., KRIESE, L.A., VAN VLECK, L.D. et al. A manual for use of MTDFREML. A set of programs to obtain estimates of variance components. US Department of Agriculture, Agricultural Research Service, Beltsville, 1995. 115p.

CAMARGO, A.J.R. Estudo de algumas características produtivas e reprodutivas de um rebanho mestiço HolandêsZebu no Estado do Rio de Janeiro. Viçosa: Universidade Federal de Viçosa, 1994. 81p. (Tese, Mestrado).

CAMPOS, M.S., WILCOX, C.J., BECERRIL, C.M. et al. Genetic parameters for yield and reproductive traits of Holstein and Jerseys in Florida. Rev. Bras. Genet., v.16, p.949-956, 1994.

DURÃES, M.C., FREITAS, A.F., TEIXEIRA, N.M. et al. Fatores de ajustamento para a produção de leite e gordura na raça Holandesa para rebanhos do Estado de Minas Gerais. Rev. Bras. Zootec., v.28, p.1248-1255, 1999.

DURÃES, M.C., KEOWN, J.F. Age-month factors mature equivalent factors for three yield traits for non-registered and registered cattle. Rev. Brasil. Genet., v.14, p.713-728, 1991.

GACULA, M.C., GAUNT, S.N., DAMON, R.A. Genetic and environmental parameters of milk constituents for five breeds. 1. Effects of herds, year, season and age of the cow. J. Dairy Sci., v.51, p.428-437, 1968.

KEOWN, J.F., EVERETT, R.W. Age-month adjustment factors for milk, fat and protein yields in Holstein cows. $J$. Dairy Sci., v.68, p.2664-2669, 1985.

MADALENA, F.E., LEMOS, A.M., TEODORO, R.L. et al. Desempenho comparativo de vacas mestiças de Holandês com Guzerá de origem leiteira e não leiteira. In: Reunião Anual da Sociedade Brasileira de Zootecnia, 33, 1996, Fortaleza. Anais ... Fortaleza: SBZ, 1996. p.3-5.

MARTINEZ, M.L. Fatores multiplicativos de ajuste da produção de leite na raça Holandesa. 1. Para os efeitos simultâneos da idade ao parto e estação de parição. Pesq. Agrop. Bras., v.26, p.1761-1770, 1991.

MARTINEZ, M.L., COSTA, C.N., TEIXEIRA, N.M. Mixed model estimation of age-season adjustment factors for milk yield of Gir cattle. Indian J. Dairy Sci., v.45, p.591-597, 1992.

MILLER, P.D., LENTZ, W.E., HENDERSON, C.R. Joint influence of month and age of calving on milk yield of Holstein cows in the Northeastern United States. J. Dairy Sci., v. 53, p.351-357, 1970.

NOBRE, P.R.C. Fatores genéticos e de meio em características produtivas e reprodutivas do rebanho leiteiro da UFV, Estado de Minas Gerais. Viçosa: Universidade Federal de Viçosa, 1983. 113p. (Tese, Mestrado)

RAMOS, A.A. Estudo das características reprodutivas e produtivas de zebuínos leiteiros da raça Gir nos trópicos. Botucatu: UNESP, 1984. 224p. (Tese, Livre Docência).

RIBAS, N., MILAGRES, J.C., SILVA, M.A. et al. Estudo da idade do primeiro parto e intervalo entre partos em rebanhos holandeses da bacia leiteira de Castrolanda, Estado do Paraná. Rev. Soc. Bras. Zootec., v.12, p.756-770, 1983.

THOMPSON, J.R., FREEMAN, A.E., BERGER, P.J. Days open adjusted annualized and fat-corrected yields as alternatives to mature-equivalent records. J. Dairy Sci., v.65, p.1562-1577, 1982. 